\title{
INFLUENCE OF COAL PROPERTIES ON THE CO-COMBUSTION CHARACTERISTICS OF LOW-GRADE COAL AND CITY MUD
}

\author{
YAN Y.F. ${ }^{1,2, *}$ \\ ZHANG Z.E. ${ }^{1,2}$ \\ ZHANG L. ${ }^{3}$ \\ ZHANG L. ${ }^{1,2}$
}

\author{
${ }^{1}$ Key Laboratory of Low-grade Energy Utilization Technologies and Systems \\ Chongqing University, Ministry of Education of PRC \\ 400044 Chongqing, China \\ ${ }^{2}$ Institute of Energy and Environment \\ Chongqing University, 400044 Chongqing, China \\ ${ }^{3}$ Huadian Electric Power Research Institute \\ 310030 Hangzhou, China
}

Received: 29/12/2013

Accepted: 13/03/2014

Available online: 20/03/2014 *to whom all correspondence should be addressed: e-mail: yunfeiyan@cqu.edu.cn

\begin{abstract}
In this paper, the effects of the mixing ratio and particle size of coal were investigated using a thermogravimetric analysis (TGA). A method of Achar-Brindley-Sharp-Wendworth (ABSW) was applied to a simultaneous calculation of the kinetic parameters (including the apparent activation energy, the reaction order and the frequency factor). Meanwhile, this study also revealed that both the burning performance and the characteristic parameters improved when sludge mixing ratio was smaller (10 wt.\%). The ignition temperature advanced with an increase of the sludge proportion, while the combustion characteristic index dropped. As the sludge mixture ratio rose to $70 \mathrm{wt} . \%$, the DTG curve reached three peaks at $293{ }^{\circ} \mathrm{C}, 580{ }^{\circ} \mathrm{C}$ and $748{ }^{\circ} \mathrm{C}$. Decreasing the coal particle size led to the advancement of the devolatilization, fixed carbon burning stage and maximum weight loss rate, and the reduction of the corresponding temperature. Additionally, the apparent activation energy and frequency factor of the mixture reduced when the proportion of the sludge mixing ratio went up. Also, the experiment results indicated that with the decline of the particle size distribution of coal, the apparent activation energy followed a downward trend, while the frequency factor increased.
\end{abstract}

Keywords: thermogravimetric analysis, mixture ratio, particle size of coal, combustion characteristics, kinetic analysis.

\section{Introduction}

With the rapid development of urbanization and industrialization, a large amount of the city mud which are one of the most important restricting factors of the urban development result in the environmental problems and energy shortage. It is necessary to dispose of wastes and greenhouse gas emissions. For the past several decades, some scholars studied the co-combustion behavior of sludge and coal. Xiao et al., (2009) investigated the combustion characteristics of sludge with straw and coal under different oxygen levels and heating temperatures using the TGA method. It was concludied that increasing the oxygen density and heating rate promoted the whole reaction. But in that case the weight loss considerably reduced with an increase in the heating rate. In addition, the co-combustion behavior of sewage sludge with coal gangue or coal were also conducted (Xiao et al., 2010). Liu et al. (2006a; 2006b) reported that the combustion characteristics were different when the samples (coal, city mud and their 
mixture) were burnt at various mixture ratios. These samples kept their separation characteristics in the co-combustion process of sludge and coal. Lou et al., (2010) analyzed the combustion process of mixing sludge in a pulverized coal furnace of a certain power plant by a computational fluid dynamics (CFD) method, and discussed the distribution of the velocity and temperature. Liao et al., (2010) observed the combustion characteristics of sludge, anthracite and their mixture under the conditions of different heating rates. The results showed that higher volatility enhanced the ignition characteristics of coal in the sludge. Zhang et al., (2011) studied the co-combustion behavior of coal and paper mill sludge at different heating rates. The experimental results indicated that the total weight loss rate and burn index gradually rose while increasing the heating rate or the sludge proportion. Yu et al., (2008) reported that the catalyst had a significant effect on the ignition and burning of straw or wheat straw in air and rich oxygen. There were also some literature concerning the co-combustion of sewage sludge and coal (Folgueras et al., 2003; Nugteren et al., 2009; Nadziakiewicz and Koziol, 2003; Otero et al., 2002, 2006, 2007; Wang et al., 2012). Folgueras et al., (2003) reported that the $50 \mathrm{wt.} \%$ sludge-coal mixture showed two different reactivity regions. The reactivity was similar to that of sludge in the lower temperature region $\left(\mathrm{T}<350{ }^{\circ} \mathrm{C}\right.$, while it was identical with that of coal in the higher temperature region $\left(\mathrm{T}>350^{\circ} \mathrm{C}\right.$. In some cases, combustion of sewage sludge or co-combustion with coal could be a good choice for its management (Otero et al., 2002). The effect of co-combustion of sludge (below $10 \mathrm{wt} . \%$ ) and coal was not apparent for the heat release and weight loss of coal when adding a bit of sludge (Otero et al., 2006, 2007).

The analysis of co-combustion has already been intensively investigated by many scholars. However, there are fewer literatures presenting the influence of particle size distribution of coal on the cocombustion performance of sewage sludge and coal. The impact of oxygen concentration on the cocombustion behavior and kinetic analysis was investigated in previous study (Yan et al., 2013). In this work, a thermogravimetric analysis is applied to investigate the co-combustion characteristics of sewage sludge with coal by changing the mixing proportion and particle size distribution of coal in the blends. Also, the ABSW method is adopted to analyze the dynamic parameters of sewage sludge with coal. Meanwhile, this work provides the reference for the co-combustion technology and application of sludge and coal in industrial boilers, which is beneficial to efficient use and treatment of inferior coal and sludge and reduces the amount of the sludge process.

\section{Experiment}

The thermogravimetry (TG) tests were carried out in a NETZSCH STA409PC simultaneous analyzer. The sample $(10 \pm 0.5 \mathrm{mg})$ was placed on an $\alpha-\mathrm{Al}_{2} \mathrm{O}_{3}$ ceramic pan. To simulate the combustion and pyrolysis processes, mixture gases ( $80 \%$ nitrogen / $20 \%$ oxygen) were used at a flow rate of $100 \mathrm{ml} \mathrm{min}^{-1}$ and a heating rate of $20 \mathrm{~K} \mathrm{~min}^{-1}$, then falling to the ambient temperature. At the same time, the oxygen pressure and nitrogen pressure were $0.04 \mathrm{Mpa}$.

Table 1. Ultimate Analysis of Samples

\begin{tabular}{ccccc}
\hline Sample & $\mathbf{M}_{\mathrm{ad}}(\%)$ & $\mathbf{V}_{\mathrm{ad}}(\%)$ & $\mathbf{A}_{\mathrm{ad}}(\%)$ & $\mathbf{F C}_{\mathrm{ad}}(\mathbf{\%})$ \\
\hline Low-grade coal & 0.84 & 16.97 & 28.85 & 53.34 \\
\hline City mud & 2.97 & 27.89 & 67.85 & 1.30 \\
\hline
\end{tabular}

Low-grade coals were collected from Chongqing City and sludge was obtained from the wastewater treatment plant which was the largest wastewater treatment industry in the southwest of China. Firstly, the low-grade coal was milled and sieved into less than 200 mesh in diameter. The sewage sludge was dried in oven at $85^{\circ} \mathrm{C}$ for $24 \mathrm{~h}$, and then was milled and sieved into below 200 mesh. The samples were kept under seal in a constant drying temperature and ready for use. Last, the sludge was mixed with the same particle-size coal in various ratios in the fuel blend. Furthermore, in order to ensure the homogeneous mixing samples and the repetition of the TGA experiments, after blending well, the samples with same mixing ratio are selected randomly to do the technical analysis. The amount of every ratio of samples is 10 . Thus, these preparations are conducted to ensure the reproducibility of TGA 
experiments. The technical analysis of samples were carried out in a YX-GYFX7701 automatic industrial analyzer. Table 1 indicates that sludge has higher water content $\left(M_{a d}\right)$, volatile matter $\left(V_{a d}\right)$ and ash content $\left(\mathrm{V}_{\mathrm{ad}}\right)$, and lower fixed carbon $\left(\mathrm{FC}_{\mathrm{ad}}\right)$ compared to coal. Figure 1 shows the Scanning Electron Microscopes (SEM) micrograph of coal and city mud. From the figure, it can be seen that the structure of coal is angular and more rigid than that of sludge.

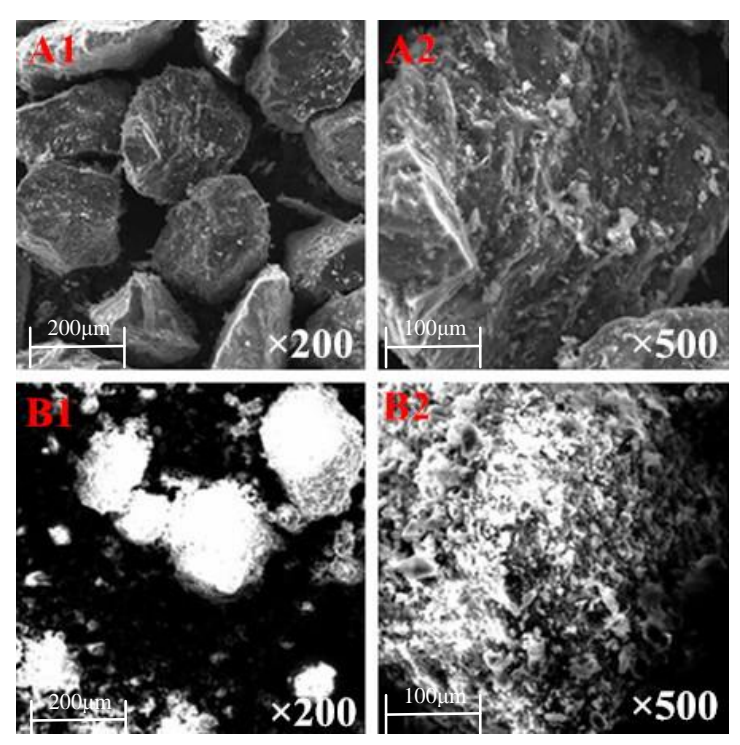

Figure 1. SEM micrograph of samples (A) coal and (B) city mud

\section{Results and discussion}

\subsection{Combustion characteristics analyses}

\subsubsection{Ignition temperature and burning temperature}

The ignition temperature is not only the lowest burning temperature of fuel, but the major index of the ignition performance. Actually lower ignition temperature results in better ignition performance. The TG-DTG method was used in the experiments to obtain the ignition temperature $T_{i 1}$ of sludge, the ignition temperature $T_{i 2}$ of inferior coal, and the burnout temperature $T_{b}$. Additionally, $T_{b}$ is defined as the temperature of weight loss which accounts for about $98 \%$ of the total weight loss in the sample (Figure 2).

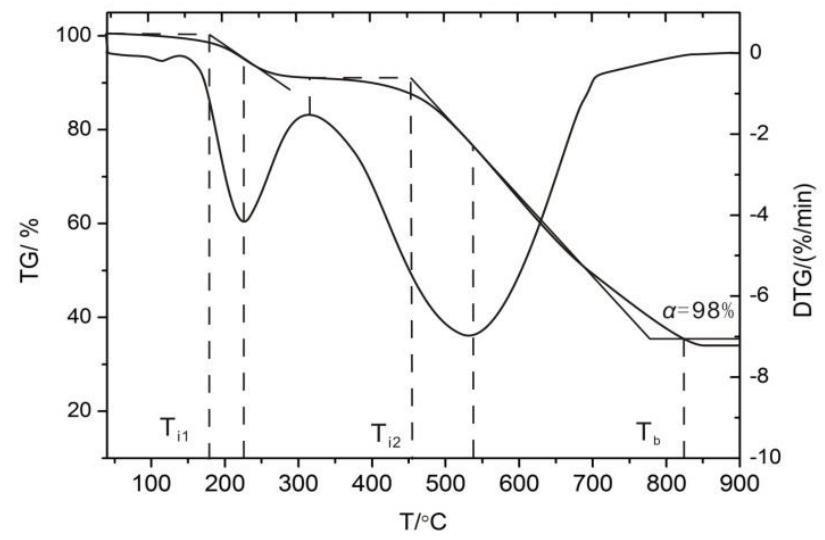

Figure 2. Demonstration of ignition point and burnout point 


\subsubsection{Combustibility index}

The ignition temperature only represents the response ability of fuel combustion in the initial stage. The combustibility index $\mathrm{C}$ reflects the combustion characteristics of fuel. Higher combustibility index has better fuel burning stability. It could be calculated by Sun (2002):

$\mathrm{C}=(\mathrm{dW} / \mathrm{dt})_{\max } / \mathrm{T}$

\subsubsection{Comprehensive combustion characteristic index}

The comprehensive combustion characteristic index $\mathrm{S}$ represents the ignition and burnout performance of the sample. Higher value of $\mathrm{S}$ has better comprehensive combustion performance. It is defined as follows (Jiang et al, 2000):

$$
S=\frac{(d w / d t)_{\max }(d w / d t)_{\text {mean }}}{T_{i}^{2} T_{b}}
$$

where $(d W / d t)_{\max }$ is the largest burning rate and $(d W / d t)_{\text {mean }}$ is the average burning rate. $T_{i}, T_{b}$ denote the ignition temperature and the burnout temperature, respectively.

In order to observe the influence of the mixing ratio of sludge, the mixture combustible index $C_{M}$ and the comprehensive combustion characteristic index $S_{M}$ are the most significant indexes of the reaction which may be written:

$$
\begin{aligned}
& C_{M}=\frac{\sum_{j=1,2}\left(d w_{j} / d t\right)_{\max }}{\left[\frac{\sum_{j=1,2} T_{i j}}{2}\right]^{2}}
\end{aligned}
$$

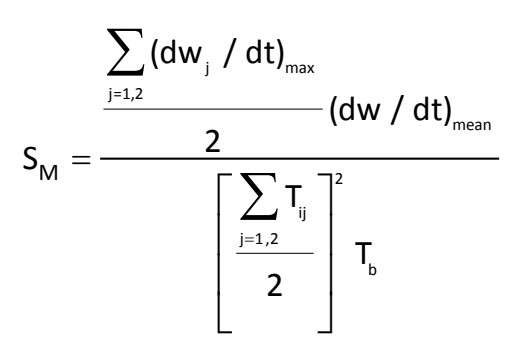

In equation $\frac{\sum_{\mathrm{j}=1,2}\left(\mathrm{~d} \mathrm{w}_{\mathrm{j}} / \mathrm{dt}\right)_{\max }}{2}$

(3), denotes the arithmetic co-firing volatilization burning peak and

fixed carbon weightlessness peak in the early stage. $\left[\frac{\sum_{j=1,2} T_{i j}}{2}\right]^{2}$ represents the arithmetic average square of the ignition temperature of sludge and coal.

In equation (4), $\frac{\sum_{\mathrm{j}=1,2}\left(\mathrm{dw_{j }} / \mathrm{dt}\right)_{\max }}{2}$ is the arithmetic average value of burning peak of the volatilization

of sludge and the weightlessness rate of weight loss peak of fixed carbon in the later stage. $(\mathrm{dw} / \mathrm{dt})_{\text {mean }}$ denotes the average weightlessness rate of mixture between the ignition and burnout. 


\subsection{TG and DTG analysis of sludge and inferior coal under different mixing ratios}

First of all, the inferior coal of 120-150 mesh size were used in the experiments. Figure 3 displays the TG and DTG profiles for sewage sludge and coal. Seven different mixing proportion of sludge samples (0 wt.\%, 10 wt.\%, 20 wt.\%, 30 wt.\%, 50 wt.\%, 70 wt.\% and 100 wt.\%) were heated from ambient temperature to $900^{\circ} \mathrm{C}$ at the heating rate of $20 \mathrm{~K} \mathrm{~min}^{-1}$ and the artificial air velocity of $100 \mathrm{ml} \mathrm{min}^{-1}$. The results indicate that the curve of sludge $(100 \mathrm{wt} . \%)$ has two overlapping peaks which are at the volatile exhalation stage of volatile $\left(200-400^{\circ} \mathrm{C}\right)$ and the fixed carbon burning stage $\left(650-743^{\circ} \mathrm{C}\right)$. But the curve of inferior coal ( 0 wt.\%) only has one overlapping peak in the fixed carbon burning step $\left(380-750{ }^{\circ} \mathrm{C}\right)$. From the TG and DTG curves of coal, it can be seen that coal has weight gain phenomenon before burning $\left(200-400{ }^{\circ} \mathrm{C}\right)$. At this stage, coal has the physical and chemical adsorption effect on the surrounding environments. However, with an advancement of sludge mixing ratio the sludge volatile separates out in $200-400{ }^{\circ} \mathrm{C}$, which breaks the adsorption effect of coal, and results in no weight gain. Meanwhile, the TG curve of co-combustion is located between that of the sludge sample and the coal sample. And the weight loss remarkably reduces with an increase in the sludge mixing ratio.
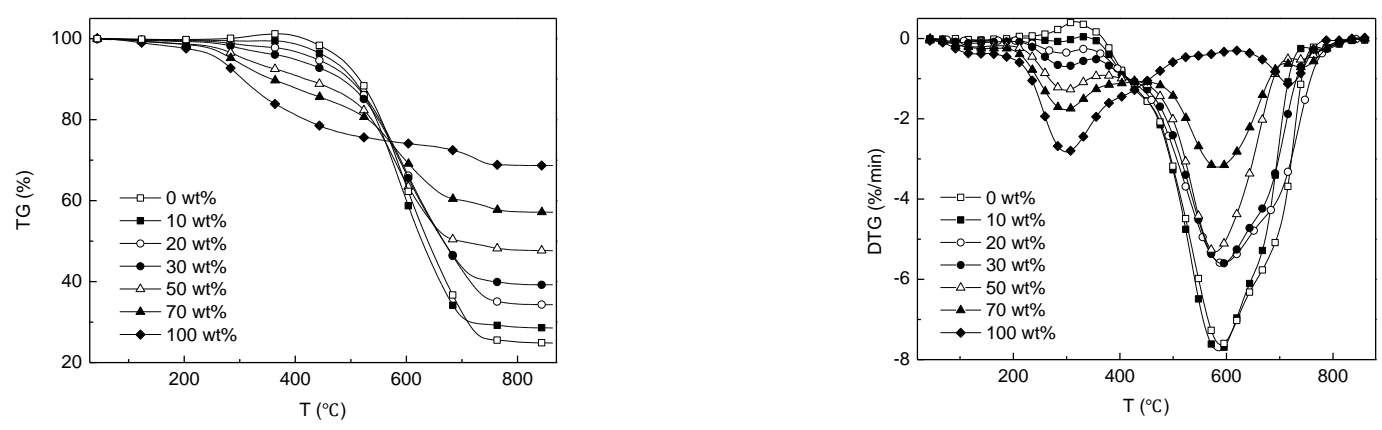

Figure 3. TG (left) and DTG (right) curves of combustion characteristics for different mixing ratios of municipal sludge and coal

When the proportion of sludge is $10 \mathrm{wt} . \%$ in the mixture, there is only one overlapping peak in the DTG curve. With the continuous separating volatile matter of sludge, the mixture ignition temperature, the biggest weight loss rate and co-combustion characteristics improve, while the corresponding temperature decreases. When the proportion of sludge increases, the mixture ash content accordingly goes up, while the total weight loss drops. And it also shows that the corresponding temperature of the biggest weight loss rate decreases.

Table 2. The combustion parameters of coal and city mud with different mixing ratios

\begin{tabular}{|c|c|c|c|c|c|c|c|}
\hline Mixing ratio & $\begin{array}{c}T_{\mathrm{i}} \\
\left({ }^{\circ} \mathrm{C}\right) \\
\end{array}$ & $\begin{array}{l}T_{\max } \\
\left({ }^{\circ} \mathrm{C}\right)\end{array}$ & $\begin{array}{c}T_{\mathrm{h}} \\
\left({ }^{\circ} \mathrm{C}\right)\end{array}$ & $\begin{array}{c}C_{M \times 10^{5}} \\
\left(\% \min ^{-1} K^{-2}\right)\end{array}$ & $\begin{array}{c}(d w / d \tau)_{\max } \\
\left(\% \min ^{-1}\right)\end{array}$ & $\begin{array}{c}(d w / d \tau)_{\text {mean }} \\
\left(\% \min ^{-1}\right)\end{array}$ & $\begin{array}{c}S_{\mathrm{M}} \times 10^{8} \\
\left(\mathrm{mg}^{2} \mathrm{~K}^{-3} \min ^{-2}\right)\end{array}$ \\
\hline Owt.\% & 503 & 597 & 735 & 3.04 & 7.69 & 5.66 & 23.4 \\
\hline 10wt.\% & 497 & 588 & 716 & 3.18 & 7.85 & 5.42 & 24.1 \\
\hline 20wt.\% & 481 & 584 & 739 & 2.46 & 5.68 & 4.21 & 14.0 \\
\hline 30wt.\% & 478 & 579 & 739 & 2.49 & 5.71 & 3.60 & 12.17 \\
\hline 50wt.\% & 470 & 575 & 739 & 1.01 & 5.65 & 2.65 & 3.63 \\
\hline 70wt.\% & 416 & 572 & 741 & 1.50 & 3.36 & 1.70 & 3.45 \\
\hline 100wt.\% & 227 & 296 & 743 & 0.61 & 2.93 & 1.17 & 0.95 \\
\hline
\end{tabular}

The DTG curve shifts from right side to left side with a wide range of the peak, which shows that adding sludge into the mixture boosts the development of ignition characteristics. When the proportion of sludge mixing is above 30 wt.\%, the DTG curve appears two peak values, which are like sludge at low 
temperatures $\left(200-400{ }^{\circ} \mathrm{C}\right)$ and similar to coal at high temperatures $\left(400-700{ }^{\circ} \mathrm{C}\right)$. As the proportion reaches 70 wt.\%, the DTG curve presents three peaks which are in the volatile separate stage $\left(200-400{ }^{\circ} \mathrm{C}\right)$, the carbon fixed of coal burning stage $\left(400-680^{\circ} \mathrm{C}\right)$ and the carbon fixed of sludge burning stage $\left(680-750{ }^{\circ} \mathrm{C}\right)$, respectively. The results demonstrate that the sludge and coal keep their combustion characteristics separately in the co-combustion process. In addition, the experimental results agree well with the theoretical trends and literature results (Gu et al. 2003; Li et al. 2008). But when adding a bit of sludge (10 wt.\%) improves the co-combustion performance mutually.

Table 2 displays the parameters of sludge and coal in the experiments. When the percentage of blending is $10 \mathrm{wt} . \%$, the biggest burn rate slightly increases, while the corresponding temperature declines. In the meantime, its combustible index and the comprehensive combustion characteristic index improve. These results reveal that adding a little of sludge would improve the ignition characteristic of coal. And it is helpful for the coal ignition and stable burning.

With the increase of mixing proportion, the maximum combustion rate, the average combustion rate and the corresponding temperature decreases, however, the ignition temperature advances. It shows that increasing the mixing proportion of sludge is beneficial to the fire of mixture, but it is bad for the stable combustion process. Because the intensity of coal burning is smaller than that of sludge. Both of the comprehensive combustion characteristic index and combustible index decline with increasing the amount of mixing sludge. Meanwhile, it is not obvious that the burning temperature changes. On the one hand, the wrapped ash on the surface of unburned particle hinder the contacting with oxygen, which postpones the combustion process. On the other hand, the sludge and coal burn independently in the co-combustion process, which leads to slight change of the burn temperature.

\subsection{The influence of coal grain size on coal co-combustion characteristics}

In order to investigate the effect of the coal particle size on the co-combustion characteristics, the mixing ratio of sludge and coal is 1:1. Figure 4 shows the TG and DTG curves under different particle size of the mixture.
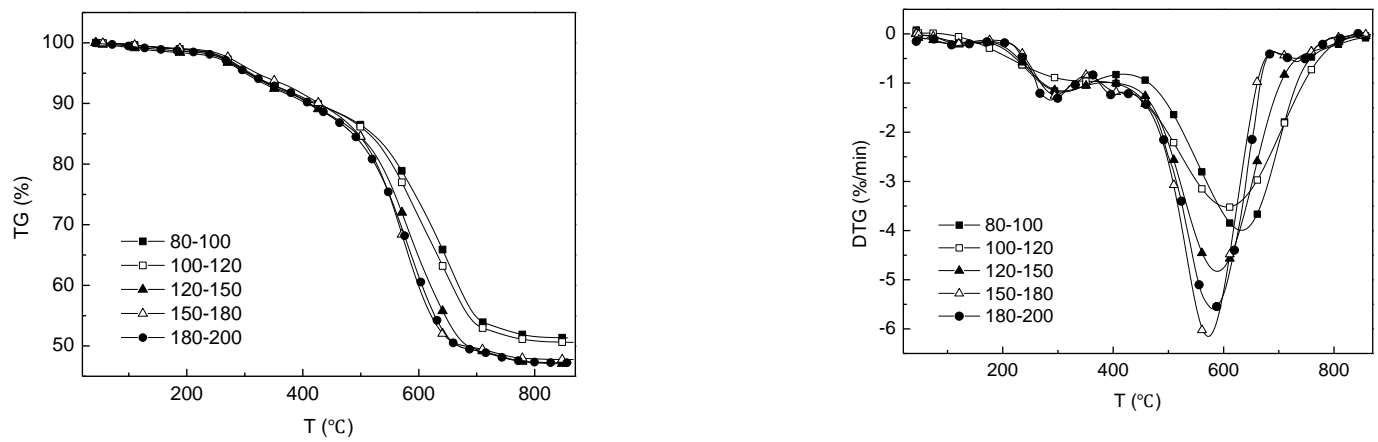

Figure 4. TG (left) and DTG (right) curves of combustion characteristics for different coal grain size

With the reduction of the particle size, the total loss gradually follows a upward trend. Moreover if the particle size changes to above 120 mesh, the weight loss gently changes about $48 \%$. While the particle size decreases (below 120 mesh), the weight loss significantly goes down to approximately $52.8 \%$. If it still declines, the total weight loss will slightly increase to $53 \%$.

From the DTG curve, the volatility of sludge separates out in the temperature range of $200-400{ }^{\circ} \mathrm{C}$. If the particle size decreases, the DTG curve shifts to the area of low temperature. Especially, when the particle size of coal is less than 120 mesh the volatilization separation enhances. Meanwhile, the decrease of the particle size has an important influence on the combustion behavior at the burning stage of fixed carbon $\left(400-700^{\circ} \mathrm{C}\right)$. Also, reducing the coal particle size results in decreasing the 
combustion temperature of coal and increasing the biggest weightlessness rate. Besides, the wave and area of peak are narrower and smaller, respectively. It is evident that the DTG curve shifts to a low temperature region. When the particle size increases (above 120 mesh), "peak shoulder" of the DTG curve is wider and the wave area is bigger. In addition, the range of the corresponding temperature is more extensive. The results show that the particle size has a great impact on the diffusion and heat transfer of gases. With the decline in the grain size of coal, the relative specific surface area, the exhalation performance of volatility in mixture, and the inhomogeneous reaction of combustion of mixture increase, however, the resistance for escaping of combustion product and heat transfer goes down.

As shown in Figure 5, the ignition temperature of co-combustion characteristic parameters gradually drops to $455^{\circ} \mathrm{C}$ from $499^{\circ} \mathrm{C}$. It shows that the burning performance improves with the decrease of the particle size of coal. Moreover, the rate of maximum weightlessness rises steadily from $4.35 \% \mathrm{~min}^{-1}$ to $5.8 \% \mathrm{~min}^{-1}$. Secondly, the corresponding temperature declines from $647{ }^{\circ} \mathrm{C}$ to $573{ }^{\circ} \mathrm{C}$, while the average burning rate climbs between $2.36 \% \mathrm{~min}^{-1}$ and $2.61 \% \mathrm{~min}^{-1}$. The combustion performance improves and the process is more reactive with the reduction of particle size of coal. Finally, the burnout temperature drops from $768{ }^{\circ} \mathrm{C}$ to $729^{\circ} \mathrm{C}$, which shows that the burning performance advances and the burnout time is shorter with the reduction of the coal particle size.

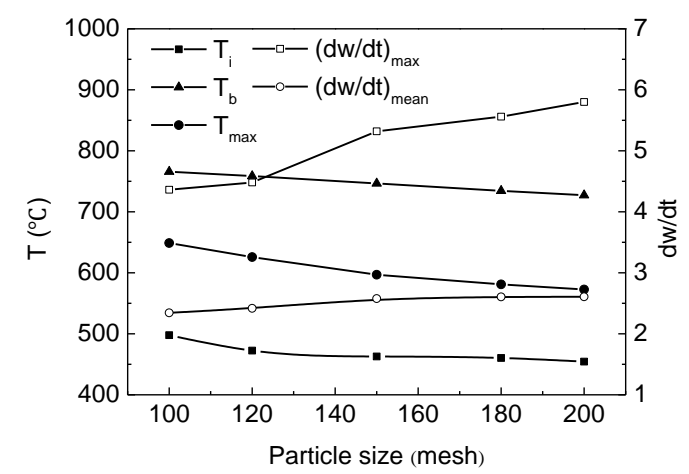

Figure 5. Influence of coal grain size on the characteristic parameters

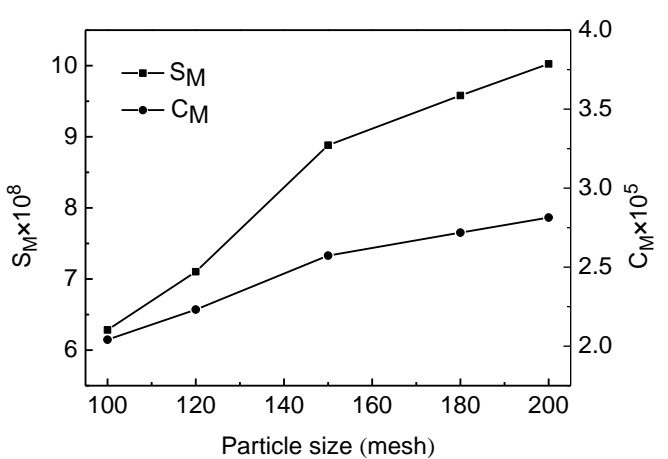

Figure 6. Influence of coal grain size on $\mathrm{S}_{\mathrm{M}}$ and $\mathrm{C}_{\mathrm{M}}$

As shown in Figure 6, it can be seen that the ignitability index rises from $2.04 \times 10^{-5} \% \mathrm{~min}^{-1} \mathrm{~K}^{-2}$ to $2.81 \times 10^{-5} \% \mathrm{~min}^{-1} \mathrm{~K}^{-2}$, the comprehensive combustion characteristics index grows up to $10.01 \times 10^{-8} \%$ $\mathrm{min}^{-1} \mathrm{~K}^{-2}$ from $6.27 \times 10^{-8} \% \mathrm{~min}^{-1} \mathrm{~K}^{-2}$. The diagram also reveals that the comprehensive combustion level increases with a decrease of the particle size of coal, which enhances the combustion performance. But it is not linear for the decrease of coal particle size and the improvement of burning characteristic parameters. The changing trend gradually slows down. So in order to make the costs and benefits more optimal, the equipment for the energy consumption should be considered in the practical applications.

\section{Calculation and analysis about the kinetics of combustion}

The dynamical equation of non-isothermal reaction can be written as follows:

$\frac{\mathrm{d} \alpha}{\mathrm{dT}}=\frac{1}{\beta} \mathrm{k}(\mathrm{T}) \mathrm{f}(\alpha)$

where $\alpha$ is the conversion degree, its definition is $\alpha=\frac{w-w_{0}}{w_{0}-w_{1}}, w$ is the residual quality (score) when the time is $\tau, T$ denotes the absolute temperature. $w_{0}$ and $w_{1}$ are the initial mass and the final quality of the 
reaction, respectively. $f(\alpha)$ is a function, the type of which depends on the reaction mechanism, the temperature dependent rate constant $k(T)$ which is usually described by the Arrhenius equation:

$k=A \exp (-E / R T)$

here $\mathrm{A}$ is the frequency factor $\left(\mathrm{s}^{-1}\right), \mathrm{E}$ is the active energy $\left(\mathrm{kJ} \mathrm{mol}^{-1}\right), \mathrm{R}$ is the universal gas constant and its value is $0.008314 \mathrm{~kJ} \mathrm{~mol}^{-1} \mathrm{~K}^{-1}$. In the reaction process of increasing temperature, $B$ could be estimated by:

$\beta=d T / d t$

For the weightlessness reaction of solid burning, $f(\alpha)$ can be derived by:

$f(\alpha)=(1-\alpha)^{n}$

where $\mathrm{n}$ represents the reaction order.

So the total reaction of the reaction process may be expressed as:

$\frac{\mathrm{d} \alpha}{\mathrm{dT}}=\frac{\mathrm{A}}{\beta} \exp \left(-\frac{\mathrm{E}}{\mathrm{RT}}\right)(1-\alpha)^{\mathrm{n}}$

$\ln \frac{\mathrm{d} \alpha}{\mathrm{dT}}=\ln \left(\frac{\mathrm{A}}{\beta}\right)-\frac{\mathrm{E}}{\mathrm{RT}}+\mathrm{n} \ln (1-\alpha)$

To make the dualistic linear fitting by the least square method, the values of $b_{0}, b_{1}, b_{2}$, the number of reaction stages $n\left(n=b_{2}\right)$, the activation energy of reaction $E\left(E=b_{1} \times R\right)$ and the frequency factor $A$ $\left[A=\exp \left(b_{0}\right) \times 6\right]$ can be obtained (Hu et al, 2008).

Meanwhile, in order to realize the linear fitting of the calculation, the user-defined function is solved in Origin 8.5.1. The two weightlessness peaks including the extreme point and burn point are selected as the boundary range of temperature. The interzone value of $n$ increases from 0 to 3 at an increasing rate of 0.1. Finally, $\mathrm{n}$ is chosen as an optimal number of the reaction stage when the correlation coefficient $r$ is largest. Tables 3 and 4 show the calculation results of dynamic parameters.

Table 3. Dynamic parameters under different sludge mixture proportions

\begin{tabular}{cccccc}
\hline Mixing ratio & $\mathbf{T}\left({ }^{\circ} \mathbf{C}\right)$ & $\mathbf{n}$ & $\mathbf{E}\left(\mathbf{k J ~ k g}^{-\mathbf{1}}\right)$ & $\mathbf{A ~}\left(\mathbf{s}^{-\mathbf{1}}\right)$ & $\mathbf{r}$ \\
\hline 0 wt.\% & $503-735$ & 1.1 & 104.82 & 96054 & 0.990 \\
\hline 10 wt.\% & $497-716$ & 1.2 & 88.06 & 54782 & 0.991 \\
\hline 20 wt.\% & $481-739$ & 0.9 & 76.68 & 8348 & 0.987 \\
\hline 30 wt.\% & $478-739$ & 1.1 & 68.35 & 2415 & 0.986 \\
\hline 50 wt.\% & $470-739$ & 1 & 65.80 & 1852 & 0.983 \\
\hline 70 wt.\% & $416-741$ & 1.3 & 63.08 & 1678 & 0.984 \\
\hline 100 wt.\% & $227-743$ & 3.5 & 35.07 & 730 & 0.981 \\
\hline
\end{tabular}

As shown in Table 3, it can be seen that the correlation coefficient of the linear fitting is above 0.981 at different sludge mixing ratios, which has high linearity and good fitting effect. With the increase of the mixing ratio of sludge, the apparent activation energy and the frequency factor of the mixture decline (Lou and Wang, 2011). However, the reducing trend gradually slows down, which is due to the coal (or other fuels) regarded as the composition of the activation energy distributed from low to high. While the sludge mixing ratio goes up, the ignition temperature elevates. The combustion reaction moves to the low temperature area. The material of high activation energy can be reacted at low temperature. At the same time, the apparent activation energy increases during the low-temperature period, which leads to a downward trend. The frequency factor reflects the activity of material internal molecules at certain temperatures. The activity of the sludge is lower than that of coal. The frequency factor decreases with the growth of the sludge ratio. 
Table 4 illustrates with the decline of the coal particle size, the apparent activation energy has a minor reduction, while frequency factor rises. The results reveal that smaller particle size of coal has bigger specific surface area. The contacting and collision with oxygen promote the frequency factor. For the same kind of coal, with the decline in particle size, the content of volatilizing and fixed carbon increases. Relatively, the content of ash decreases. And this is an external macroscopic expression when the structure of coal microcosmic granule is affected by various particle sizes. With the decrease of the particle size of coal, the heat reactivity is more rapid and the heat easily releases from the combustion products. Furthermore, the combustion performance improves. From performance of the macro effect, It can be seen that when absorbing less heat, the burning process keeps on going and the activation energy reduces.

Table 4. Dynamic parameters under different particle size distribution of coal

\begin{tabular}{cccccc}
\hline $\begin{array}{c}\text { Particle size } \\
\text { (mesh) }\end{array}$ & $\mathbf{T}\left({ }^{\circ} \mathbf{C}\right)$ & $\mathbf{n}$ & $\mathbf{E}\left(\mathbf{k J ~ k g}^{-\mathbf{1}}\right)$ & $\mathbf{A}\left(\mathbf{s}^{-1}\right)$ & $\mathbf{r}$ \\
\hline $80-100$ & $475-768$ & 1 & 68.57 & 1048 & 0.986 \\
\hline $100-120$ & $469-758$ & 1 & 67.63 & 1537 & 0.983 \\
\hline $120-150$ & $465-747$ & 1 & 65.59 & 1875 & 0.984 \\
\hline $150-180$ & $460-735$ & 1 & 59.58 & 2004 & 0.992 \\
\hline $180-200$ & $450-699$ & 1 & 54.57 & 2107 & 0.996 \\
\hline
\end{tabular}

\section{Conclusions}

1) The co-combustion characteristics of sludge and coal are the results of their joint action. In the cocombustion process, both of them keep their original combustion characteristics separately. When the mixing ratio of sludge is small (10 wt\%), they have strong synergy and acceleration, which promotes the co-combustion performance and burning process. If the proportion of sludge is bigger, it is beneficial to stable combustion and harmful to the ignition.

2) With the decrease of the particle size of coal, the weight loss of mixture increases from $48 \%$ to $53 \%$, which accelerates the separation of volatile. Meanwhile, the combustion process becomes fiercer. Additionally the ignition temperature, the maximum of weight loss rate, and the burnout temperature reduce, while the combustible index and the comprehensive combustion characteristic index increase. Thus, the comprehensive burning level improves.

3) With the increase in the mixing ratio of sludge, the apparent activation energy reduces from 104.82 $\mathrm{kJ} \mathrm{kg}^{-1}$ to $35.07 \mathrm{~kJ} \mathrm{~kg}^{-1}$, and the frequency factor falls from $96054 \mathrm{~s}^{-1}$ to $730 \mathrm{~s}^{-1}$. Moreover if the particle size of coal decreases, the relative specific surface area gradually increases, and the resistance of the combustion reduces. Specifically the apparent activation energy reduces to 54.57 $\mathrm{kJ} \mathrm{kg}^{-1}$ by $68.57 \mathrm{~kJ} \mathrm{~kg}^{-1}$, and the frequency factor increases from $1048 \mathrm{~s}^{-1}$ to $2107 \mathrm{~s}^{-1}$.

\section{Acknowledgment}

This work was supported by the Fundamental Research Funds for China National Tobacco Corp Chongqing Branch (Project No.NY20130501010010) and the Central Universities (Project No.CDJZR10140011).

\section{References}

Folgueras A.B., Diaz R.M., Xiberta J. and Prieto I. (2003), Thermogravimetric analysis of the co-combustion of coal and sewage sludge, Fuel, 82, 2051-2055.

Gu L.F., Chen X.P., Zhao C.S. and Wu X. (2003), Utilizing thermogravimetric to research the burning of city mud and coal powder, Journal of Engineering for Thermal Energy and Power, 18, 561-563.

Hu R.Z., Gao S.L., Zhao F.Q., Shi Q.Z., Zhao T.L. and Zhang J.J. (2008), Thermal Analysis Kinetic, Second Edition, Science Press, Beijing. 
Jiang X.M., Li J.B. and Qiu J.R. (2000), Study on combustion characteristic of micro-pulverized coal, Proceedings of the CSEE, 20, 34-74.

Li P.S., Li J., Hu Y. and Yu W. (2008), Combustion reaction kinetics of sewage sludge/coal mixtures based DTA method, Journal of Huazhong University of Science and Technology, 36, 119-121.

Liao, Y.F. and Ma, X.Q. (2010), Thermogravimetric analysis of the co-combustion of coal and paper mill sludge, Applied Energy, 87, 3526-3532.

Liu L., Li L.P., Zhou J.M., Yan X.Z. and Tu F.B. (2006a), Thermogravimetric analysis of co-combustion of coal and sewage sludge, Journal of North China Electric Power University, 33, 76-79.

Liu L., Li L.P., Zhou J.M., Yan X.Z. and Yan H.J. (2006b), Investigation on the co-combustion characteristics of coal and sewage sludge by thermogravimetric analysis, Acta Scientiae Circumstantiae, 26, 835-839.

Lou B. and Wang X.C. (2011), Thermogravimetric analysis of co-combustion of coal and city mud, Journal of Engineering for Thermal Energy and Power, 26, 114-116.

Lou B., Wang F. and Peng X.J. (2010), Numerical simulation and analysis of incineration blending waste-water sludge in a pulverized coal combustion boiler, Journal of South China University of Technology, 38, 153-156.

Nadziakiewicz J. and Koziol M. (2003), Co-combustion of sludge with coal, Applied Energy, 75, 239-248.

Nie Q.H., Sun S.Z., Li Z.Q., Zhang X.J., Wu S.H. and Qin Y.K. (2001), Thermogravimetric analysis on the combustion characteristics of brown coal blends, Journal of Combustion Science and Technology, 7, 72-76.

Nugteren H.W., Butselaar-Orthlieb V.C.L. and Izquierdo M. (2009), High strength geopolymers produced from coal combustion fly ash, Global NEST Journal, 11, 155-161.

Otero M., Diez C., Calvo L.F., Garcia A.I. and Moran A. (2002), Analysis of the co-combustion of sewage sludge and coal by TG-MS, Biomass and Bioenergy, 22, 319-329.

Otero M., Gomez X., Garcia A.I. and Moran A. (2007), Effects of sewage sludge blending on the coal combustion: a thermogravimetric assessment, Chemosphere, 69, 1740-1750.

Otero M., Sanchz M.E., Garcia A.I. and Moran A. (2006), Simultaneous thermogravimetric-mass spectrometric study on the co-combustion of coal and sewage sludges, Journal of Thermal Analysis and Calorimetry, 86, 489-495.

Sun X.X. (2002), Coal-Fired Boiler Combustion Experimental Techniques and Methods, First Edition, China Electric Power Press, Beijing.

Wang X.B., Si J.P., Tan H.Z., Niu Y.Q., Xu C. and Xu T.M. (2012), Kinetics investigation on the combustion of waste capsicum stalks in Western China using thermogravimetric analysis, Journal of Thermal Analysis and Calorimetry, 109, 403-412.

Xiao H.M., Ma X.Q. and Lai Z.Y. (2009), Isoconversional kinetic analysis of co-combustion of sewage sludge with straw and coal, Applied Energy, 86, 1741-1745.

Xiao H.M., Ma X.Q. and Liu K. (2010), Co-combustion kinetics of sewage sludge with coal and coal gangue under different atmospheres. Energy Conversion and Management, 51, 1976-1980.

Yan Y.F., Zhang L., Zhang L., Lei Q. and Zhang J. (2013), Influence of oxygen concentration on combustion characteristics of inferior coal and sludge mixture, Journal of Fuel Chemistry and Technology, 41, 430-435.

Yu Z.S., Ma X.Q. and Liu A. (2008), Kinetic studies on catalytic combustion of rice and wheat straw under air-and oxygen-enriched atmospheres by using thermogravimetric analysis, Biomass and Bioenergy, 32, 1046-1055.

Zhang N., Ning X.A., Zhou J.B., Wei P.T., and Luo H.J. (2011), Investigation on the co-combustion characteristics of pulverized coal and paper mill sludge, Applied Mechanics and Materials, 55-57, 1132-1137. 